\title{
Chemotherapy-related striate melanonychia: a case report
}

\author{
Fazleenah Hussain ${ }^{1 *}$, Dushyanth Gnanappiragasam ${ }^{2}$ [D and Freida Shaffrali ${ }^{1}$
}

\begin{abstract}
Background: Chemotherapy medications are reported to cause discoloration of the nails known as melanonychia. Depending on the nail structure affected and the severity of the insult, the clinical features can be variable. There are a great deal of unreported cases of pigmentary nail changes associated with chemotherapy treatment. By sharing our knowledge, we hope to raise the awareness of these nail changes amongst clinicians. Early recognition is crucial to allay anxiety among patients and avoid any unnecessary investigations.

Case presentation: We present a case of 36-year-old woman of south Asian origin, who developed dark pigmentation in the left thumb nail during neoadjuvant chemotherapy with 5-fluorouracil, epirubicin, cyclophosphamide, and docetaxel (FEC-D) for triple negative breast cancer. Upon examination, the left thumb nail pigmentation was strikingly linear, uniform, and well demarcated extending from proximal nail fold to free margin. Despite the reassuring clinical features, the patient was understandably anxious that this could be a presentation of acral melanoma and was referred to the plastic surgeons for a nail matrix biopsy. Biopsy reassuringly was reported as melanosis and a diagnosis of striate melanonychia was made. The patient was discharged after 2-year follow-up.

Conclusion: Chemotherapy medications have improved survival rates and patient outcomes. It is important for clinicians to be aware of the association of melanonychia with certain chemotherapy medications to reduce anxiety and allow successful management of these patients without delay. Striate melanonychia in this patient was felt most likely due to the synergistic effect of chemotherapy drugs compounded with racial predisposition. Chemotherapy agents most likely to have contributed include cyclophosphamide, docetaxel, and 5-fluorouracil.
\end{abstract}

Keywords: Striate melanonychia, Chemotherapy, Nail pigmentation, Case report

\section{Background}

Melanonychia is defined as brown or black discoloration of the finger or toe nails. There are a multitude of causes for melanonychia. Depending on the nail structure affected and the severity of the insult, the clinical features can be variable. Nail changes can involve single, multiple, or all of the nails. A thorough history, direct clinical and dermatoscopy examination usually aid in diagnosis; however, histology examination remains the gold standard investigation. Chemotherapy medications have

*Correspondence: fazleenah12@hotmail.com

${ }^{1}$ Department of Dermatology, University Hospital Monklands, Airdrie ML6 0JS, UK

Full list of author information is available at the end of the article been associated with a variety of nail changes and infrequently reported to cause melanonychia. The diagnosis and management of chemotherapy medications related to melanonychia can often present a unique challenge to clinicians. Benign causes of melanonychia most often benefit from watch and wait approach. Any suspicious malignant lesions should be excised and melanonychia due to infectious causes managed with antimicrobials. We present a case of 36-year-old female who developed dark pigmentation in the left thumb nail during neoadjuvant chemotherapy with 5-fluorouracil, epirubicin, cyclophosphamide, and docetaxel (FEC-D) for triple negative breast cancer. Our patient had a nail biopsy which original author(s) and the source, provide a link to the Creative Commons licence, and indicate if changes were made. The images or other third party material in this article are included in the article's Creative Commons licence, unless indicated otherwise in a credit line to the material. If material is not included in the article's Creative Commons licence and your intended use is not permitted by statutory regulation or exceeds the permitted use, you will need to obtain permission directly from the copyright holder. To view a copy of this licence, visit http://creativecommons.org/licenses/by/4.0/. The Creative Commons Public Domain Dedication waiver (http://creativeco mmons.org/publicdomain/zero/1.0/) applies to the data made available in this article, unless otherwise stated in a credit line to the data. 
showed melanosis with no evidence of atypia. She was discharged after a period of follow-up.

\section{Case presentation}

We present a case of a 36-year-old Asian female who initially noticed a right breast lump. She was reviewed by the breast surgeons and biopsy confirmed triple negative (estrogen receptor, progesterone receptor, and human epidermal growth factor receptor 2) breast cancer. Ultrasound-guided biopsy of the right axillary node was negative. Neoadjuvant FEC-D chemotherapy was commenced together with monthly goserelin as ovarian protection with eight cycles given in total. She also received granulocyte colony-stimulating factor (G-CSF) to prevent neutropenia.

She tolerated the FEC-D chemotherapy well apart from an episode of grade 1 thrush and migraine. This was treated with nystatin, fluconazole, and co-codamol. She also attended the accident and emergency department for urinary tract infection and was prescribed trimethoprim. She was not on other medications at that time. She received adjuvant two-field radiotherapy and a boost to increase the amount of radiation delivered to the area at highest risk of breast cancer recurrence. She underwent wide local excision and sentinel lymph node biopsy 5 months after initiation of chemotherapy.

The patient noticed dark pigmentation of her left thumb nail a few days after the second cycle of chemotherapy. Over the next few months, the linear pigmentation on her thumb nail became darker. She denied pain, bleeding, or preceding history of trauma. There was no toenail involvement. She did not have any previous skin disease including psoriasis or lichen planus.

On presentation to the dermatology department, the left thumb nail pigmentation was linear, uniform, and well demarcated extending from proximal nail fold to free margin (Fig. 1a, b). Hutchinson's sign was negative. No other nails were involved, and no rash noted elsewhere. There was no pigmentation of the oral mucosa. Patient was otherwise clinically well. Blood tests including full blood count, renal profile, liver function test, HbA1c, thyroid function test, erythrocyte sedimentation rate, lipid profile, coagulation profile, B12, folate, iron studies, phosphate, and magnesium were all in the normal range.

At 12-month follow-up after initial review, the appearance was stable and was suggestive of striate melanonychia. At 24 months follow-up, the changes remained stable. Despite the reassuring clinical features, the patient was understandably anxious whether this might be a presentation of acral melanoma given her history and was referred to the plastic surgeons for a nail matrix biopsy. Biopsy reassuringly was reported as melanosis (Figs. 2, 3, 4). Figures 2 and 3 show evidence of central
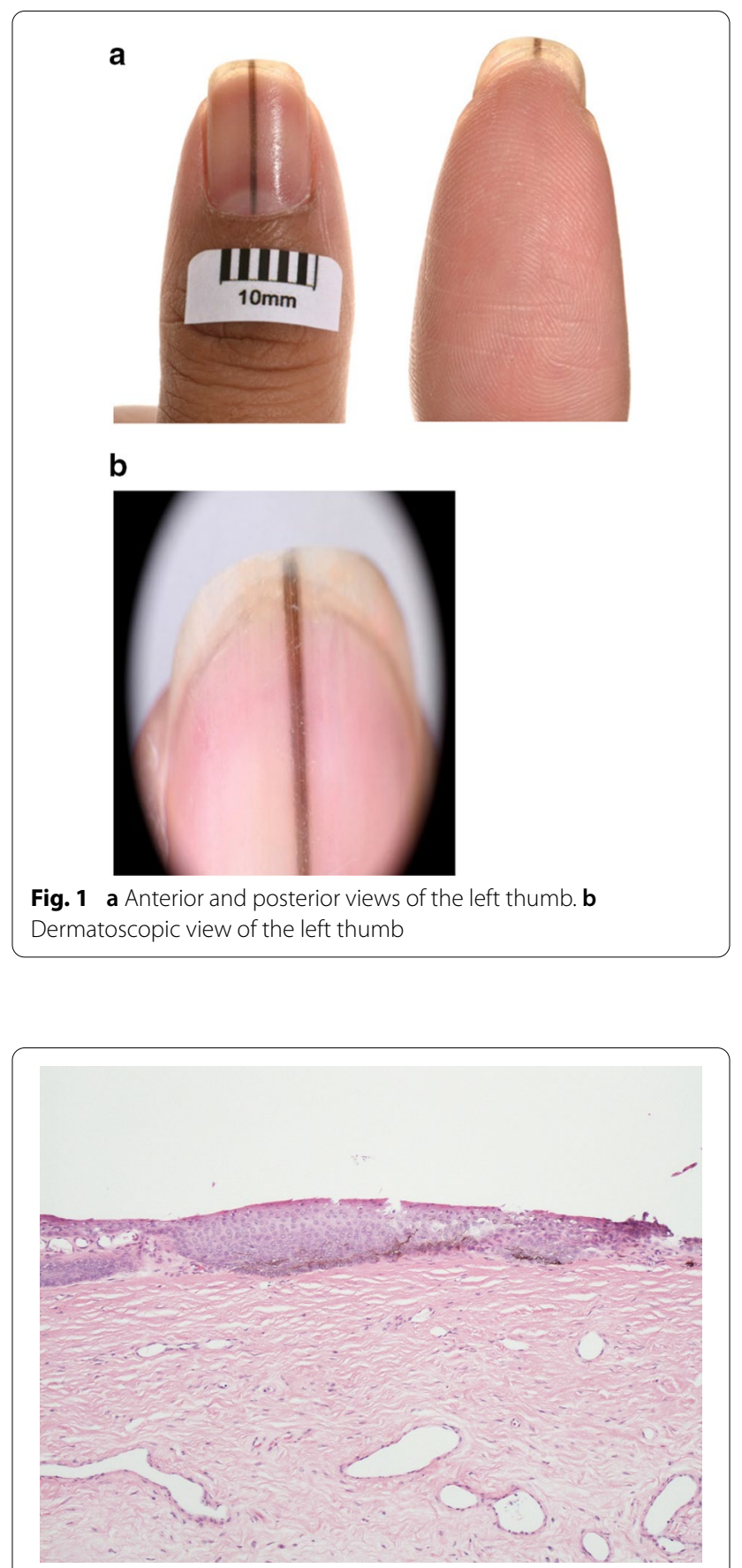

Fig. 2 Hematoxylin and eosin stain, $\times 100$

pigmentation which was confirmed as melanin with positive staining with Masson Fontana (Fig. 4). There is no evidence of significant atypia noted.

Striate melanonychia in this lady was felt most likely due to the synergistic effect of chemotherapy drugs compounded with racial predisposition. Chemotherapy agents most likely to have contributed include 


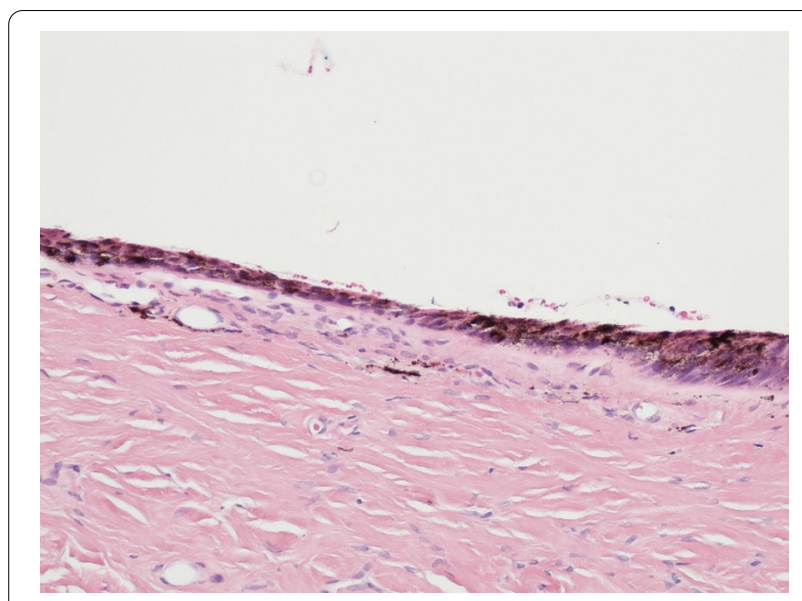

Fig. 3 Hematoxylin and eosin stain, $\times 200$

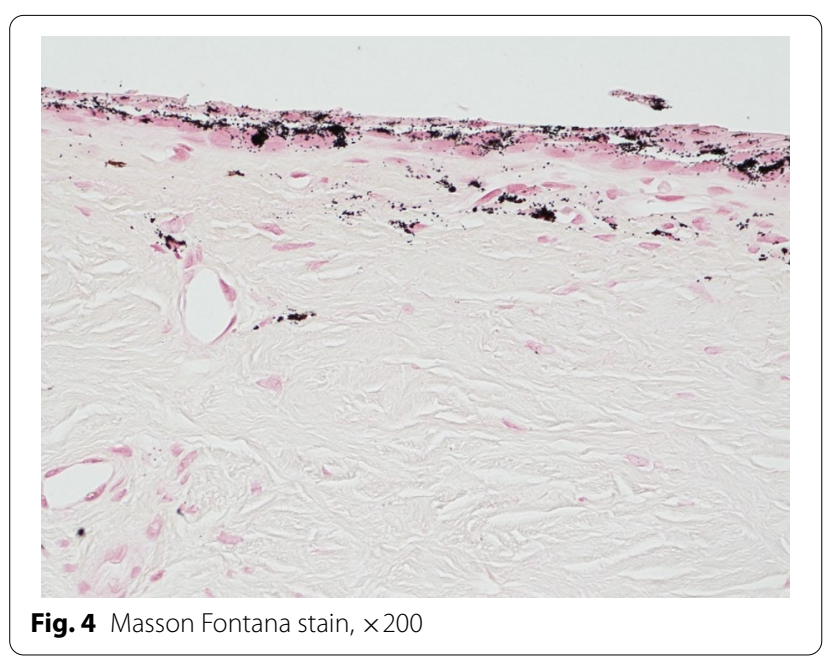

cyclophosphamide, docetaxel, epirubicin and 5-fluorouracil (Tables 1 and 2) [1, 2].

\section{Discussion}

Nail changes often provide important diagnostic clues and can be seen in inflammatory conditions, systemic diseases, diseases of specific organ systems, or associated with syndromes and genodermatoses. For example, koilonychia is seen in iron deficiency anemia, pitting of nails seen in psoriasis, and V-shaped notch can be seen in Darier's disease [3].

Melanonychia is characterized by brown to black discoloration of the nail plate [4]. Melanonychia can be associated with genetic disorders, systemic diseases, nutritional deficiencies, connective tissue disorders, inflammatory skin disease, medications, nail injury, trauma and infection. Melanonychia can be a result
Table 1 Drugs associated with longitudinal melanonychia [1]

\begin{tabular}{|c|c|}
\hline Chemotherapeutical & $\begin{array}{l}\text { Bleomycin sulfate, busulfan, cyclophosphamide, } \\
\text { dacarbazine, daunorubicin hydrochloride, } \\
\text { doxorubicin, etoposide, 5-fluorouracil, hydrox- } \\
\text { yurea, imatinib, melphalan hydrochloride, } \\
\text { methotrexate, nitrogen mustard, nitrosourea, } \\
\text { tegafur }\end{array}$ \\
\hline Antibacterial & $\begin{array}{l}\text { Sulfonamide, minocycline, roxithromycin, } \\
\text { clofazimine }\end{array}$ \\
\hline Antifungal & Ketoconazole, fluconazole, voriconazole \\
\hline Antimalarial & Chloroquine, mepacrine, amodiaquine \\
\hline Others & $\begin{array}{l}\text { ACTH, amorolfine, arsenic, chloroquine, } \\
\text { clomipramine, cyclones, fluorides, gold salts, } \\
\text { ibuprofen, lamivudine, mercury, MSH, PCB, } \\
\text { phenytoin, phenothiazine, psoralen, steroids, } \\
\text { thallium, timolol, zidovudine }\end{array}$ \\
\hline
\end{tabular}

$A C T H$ adrenocorticotropic hormone, $M S H$ melanocyte-stimulating hormone, $P C B$ polychlorinated biphenyl

Table 2 List of drugs relevant to our case and their association with melanonychia (Litt's Drug Eruption Manual, 22nd edition) [2]

\begin{tabular}{ll}
\hline Cyclophosphamide & Melanonychia, nail pigmentation \\
Docetaxel & Melanonychia, nail pigmentation \\
Epirubicin & Nail pigmentation \\
5 -Fluorouracil & Nail pigmentation \\
Goserelin & No nail pigmentary changes reported \\
Metoclopramide & No nail pigmentary changes reported \\
Ondansetron & No nail pigmentary changes reported \\
Dexamethasone & No nail pigmentary changes reported
\end{tabular}

of melanocytic hyperplasia or melanocytic activation (Table 3). Striata melanonychia and longitudinal melanonychia are synonymous terms used in the literature and in most case reports. Longitudinal melanonychia is the most common form of the presentation and transverse melanonychia and diffuse melanonychia are also infrequently encountered [5].

Melanocytic activation is an increase in the activity of melanocytes resulting in increased melanin synthesis in the nail matrix and deposition in the nail plate. A wide range of factors can induce melanocytic activation. Drug-induced melanonychia is hypothesized to be due to melanocytic activation combined with increased melanin synthesis and deposition [6]. Chemotherapy medications can be associated with a variety of nail changes including melanonychia, onychomadesis, onycholysis, leukonychia, Beau's line, nail plate abnormalities (brittle or thin nail), alteration of nail growth rate and subungual hemorrhage. 
Table 3 Conditions associated with melanonychia due to melanocytic activation and melanocytic hyperplasia in the nail matrix [1]

\begin{tabular}{|c|c|}
\hline \multicolumn{2}{|c|}{ Melanocytic activation in the nail matrix } \\
\hline Physiologic causes & $\begin{array}{l}\text { Racial } \\
\text { Pregnancy }\end{array}$ \\
\hline Local and regional causes & $\begin{array}{l}\text { Repeated local trauma from poor footwear or } \\
\text { overriding toes } \\
\text { Onychotillomania } \\
\text { Nail biting } \\
\text { Occupational trauma } \\
\text { Carpal tunnel syndrome }\end{array}$ \\
\hline Dermatologic causes & $\begin{array}{l}\text { Onychomycosis } \\
\text { Chronic paronychia } \\
\text { Psoriasis } \\
\text { Lichen planus } \\
\text { Amyloidosis } \\
\text { Chronic radiation dermatitis } \\
\text { Systemic lupus erythematosus } \\
\text { Localized scleroderma } \\
\text { Onychomatricoma } \\
\text { Bowen's disease } \\
\text { Myxoid pseudocyst } \\
\text { Basal cell carcinoma } \\
\text { Subungual fibrous histiocytoma } \\
\text { Verruca vulgaris } \\
\text { Subungual linear keratosis }\end{array}$ \\
\hline Systemic causes & $\begin{array}{l}\text { Endocrine (Addison's, Cushing's syndrome) } \\
\text { Nelson's syndrome, hyperthyroidism, acromegaly } \\
\text { Alcaptonuria } \\
\text { Nutritional disorders } \\
\text { Hemosiderosis } \\
\text { Hyperbilirubinemia } \\
\text { Porphyria } \\
\text { Graft versus host disease } \\
\text { AIDS }\end{array}$ \\
\hline latrogenic causes & $\begin{array}{l}\text { Phototherapy } \\
\text { X-ray exposure } \\
\text { Electron beam therapy } \\
\text { Drug intake }\end{array}$ \\
\hline Syndromes & $\begin{array}{l}\text { Laugier-Hunziker syndrome } \\
\text { Peutz-Jeghers syndrome } \\
\text { Touraine syndrome }\end{array}$ \\
\hline \multicolumn{2}{|c|}{ Melanocytic hyperplasia in the nail matrix } \\
\hline Benign & $\begin{array}{l}\text { Congenital nevi } \\
\text { Acquired nevi } \\
\text { Nail lentigo }\end{array}$ \\
\hline Neoplasm & $\begin{array}{l}\text { Subungual melanoma in situ } \\
\text { Subungual melanoma } \\
\text { Subungual pigmented Bowen disease } \\
\text { Subungual pigmented squamous cell carcinoma }\end{array}$ \\
\hline
\end{tabular}

Nail matrix contains actively dividing cells and can be affected by the antimitotic property of the chemotherapy medications as a result [7]. In a study consisting of 150 patients undergoing chemotherapy, pigmentary nail changes were the common nail change reported [5]. Longitudinal melanonychia was seen in $67.7 \%$ of patients on platinum-based chemotherapeutic agents and $16.1 \%$ of patients on the cyclophosphamide, doxorubicin, vincristine, and prednisolone (CHOP) regime in this study. Transverse and diffuse melanonychia patterns have also been described in patients undergoing chemotherapy treatment [8].

Melanocytic hyperplasia refers to increase in the proliferation of melanocytes in the nail matrix and nail plate. It can be induced by benign or malignant causes. Often in patients presenting with any form of melanonychia, 
subungual melanoma needs to be considered and ruled out. Subungual melanoma usually carries a poor prognosis. Late presentation could be a potential contributing factor for the delay in diagnosis. Variation in width, longitudinal band with either triangular or pyramidal shape, pigment heterogeneity, Hutchinson's sign, symptoms such as pain, bleeding, and persistent secondary infection can be features associated with suspected subungual melanoma [9]

As listed in Table 3, melanonychia can also be seen commonly in some racial types. Darker-skinned people such as black, Asian, Hispanic, and Middle Eastern individuals frequently have benign longitudinal melanonychia $[2,10]$. It is plausible that in dark-skinned patients, such as in our case, they may already had subtle early melanonychia changes to some degree even before commencing on new therapeutics which may not have been noticed before. Starting on new therapeutics such as chemotherapy medications perhaps contributes towards the accentuation of the melanonychia and it becoming visibly noticeable.

There is no effective treatment to reverse melanonychia due to the transient impairment and arrest of nail matrix mitotic activity. Some nail abnormalities often would improve over time with nail growth. It is imperative to educate patients regarding the potential melanonychia changes and providing practical strategies where applicable.

\section{Conclusion}

Chemotherapy medications have improved survival rates and patient outcomes. It is important for clinicians to be aware of the association of melanonychia with certain chemotherapy medications to reduce anxiety and allow successful management of these patients without delay. If in doubt, early dermatological review should be considered.

\section{Acknowledgements}

We would like to thank Dr. Frances Gallagher for contributing the histopathology slides in our case report.

\section{Authors' contributions}

FS was involved in conception of the case report. FS identified this interesting case after clinic review. FS conducted initial investigation and discovered the association between the chemotherapy drug and melanonychia. FS also reviewed the manuscript prior to submission. FH gained in-depth information regarding the presenting complaint and performed full examination of the patient. FH drafted the main text of the manuscript after conducting a literature search. FH also acquired the histology slides and revised the case report prior to submission. DG conducted additional literature search and substantiated the discussion. DG substantively revised the case report prior to submission. All authors read and approved the final manuscript.
Funding

The authors declare that they are in no receipt of any funding.

Availability of data and materials

Data sharing not applicable to this article as no datasets were generated or analyzed during the current study.

\section{Ethics approval and consent to participate}

This study was conducted in accordance with the fundamental principles of the Declaration of Helsinki.

\section{Consent for publication}

Written informed consent was obtained from the patient for publication of this case report and any accompanying images. A copy of the written consent is available for review by the Editor-in-Chief of this journal.

\section{Competing interests}

The authors declare that they have no competing interests.

\section{Author details}

${ }^{1}$ Department of Dermatology, University Hospital Monklands, Airdrie ML6 0JS, UK. ${ }^{2}$ Department of Dermatology, University Hospital of Leicester NHS Trust, Leicester LE1 5WW, UK.

Received: 28 July 2020 Accepted: 30 November 2020

Published online: 31 January 2021

\section{References}

1. André J, Lateur N. Pigmented nail disorders. Dermatol Clin. 2006;24(3):329-39. https://doi.org/10.1016/j.det.2006.03.012.

2. Litt JZ, Shear N. Litt's drug eruption manual. 22nd ed. Boca Raton: CRC; 2016.

3. Singh G. Nails in systemic disease. Indian J Dermatol Venereol Leprol. 2011;77:646-51. https://doi.org/10.4103/2229-5178.153002.

4. Mannava KA, Mannava S, Koman LA, Robinson-Bostom L, Jellinek N. Longitudinal melanonychia: detection and management of nail melanoma. Hand Surgery. 2013;18:133-9. https://doi.org/10.1142/S02188104133000 15.

5. Reddy PKS, Prasad ALS, Sumathy TK, Reddy RV. Nail changes in patients undergoing cancer chemotherapy. Int J Res Dermatol. 2017;3(1):49. https ://doi.org/10.18203/issn.2455-4529.IntJResDermatol20164785.

6. Haneke E, Baran R. Longitudinal melanonychia. Dermatol Surg. 2008;27(6):580-4

7. Hinds G, Thomas VD. Malignancy and cancer treatment related hair and nail changes. Dermatol Clin. 2008;26(1):59-68. https://doi.org/10.1016/j. det.2007.08.003.

8. Dasanu CA, Vaillant JG, Alexandrescu DT. Distinct patterns of chromonychia, Beau's lines, and melanoderma seen with vincristine, adriamycin, dexamethasone therapy for multiple myeloma. Dermatol Online J. 2006;12(6):10.

9. Gradinaru TC, Mihai M, Beiu C, Tebeica T, Giurcaneanu C. Melanonychiaclues for a correct diagnosis. Cureus. 2020;12(1):e6621. https://doi. org/10.7759/cureus.6621.

10. Rich P. Chapter 149 Nail surgery. In: Bolognia JL, Jorizzo JL, Rapini RP, editors. Dermatology. 2nd ed. New York: Mosby; 2006. p. 2260-8.

\section{Publisher's Note}

Springer Nature remains neutral with regard to jurisdictional claims in published maps and institutional affiliations. 